\title{
Mini-implantes: pontos consensuais e questionamentos sobre o seu uso clínico
}

\author{
Alberto Consolaro*, Eduardo Sant'ana**, Carlos Eduardo Francischone Jr***,

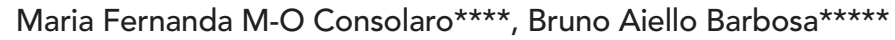

\section{PONTOS CONSENSUAIS SOBRE OS MINI-IMPLANTES}

Sobre o uso de mini-implantes na prática ortodôntica como ancoragem esquelética alguns pontos parecem ser consensuais ${ }^{1-43}$, tais como:

1. Representam uma das principais inovações na prática clínica ortodôntica dos últimos 10 anos, senão a mais relevante da Ortodontia contemporânea.

2. A ancoragem oferecida pode ser utilizada logo após a sua implantação ou até 15 dias depois. A quantidade de força inicial deve ser entre 150 e $200 \mathrm{~g}$, preferencialmente mensurada com o dinâmometro, para se evitar sobrecarga. Gradualmente, poderá ser aumentada até $350 \mathrm{~g}$, relevando-se sempre a qualidade do osso, como a espessura da cortical e a densidade óssea.

3. O seu mecanismo de ação baseia-se no imbricamento mecânico de sua estrutura metálica nas corticais e osso denso e não necessariamente no conceito da osseointegração. A forma e o comprimento das espiras são fundamentais para sua fixação. A resistência a forças de fratura pode ser aumentada com o design cônico e com espiras apropriadas para a autoperfuração. Estas características auxiliam na dissipação das forças de compressão das estruturas ósseas adjacentes ao mini- implante no ato da instalação.

4. A osseointegração, quando ocorre, dificulta a sua remoção, aumentando o risco de fratura do mesmo Por esta razão, a liga metálica de titânio que os compõe tem grau de pureza $V$. Em áreas de osso pouco denso e corticais mais finas, a osseointegração pode ser necessária e, para estes casos, a liga de titânio utilizada tem grau de pureza IV e a superfície sofre ataque ácido duplo, para aumentar a superfície de contato. Em 2007, Vannet et al..$^{39}$ (Fig. 1) posicionaram mini-implantes em cães e, exemplarmente, determinaram histomorfometricamente que a osseointegração parcial ocorria em todos os espécimes após 6 meses de ancoragem esquelética.

5. A sua implantação pode ser simples em mãos habilitadas e mentes preparadas, mas pode oferecer riscos, especialmente quando mal planejada e executada. As complicações são o contato com as raízes dentárias vizinhas, sem ou com perfuração; mucosite; contaminação e fraturas. A higienização é fundamental para sua manutenção dentro de padrões de normalidade.

6. Podem ser classificados, quanto à sua forma de aplicação, em: a) autoperfurantes, que oferecem menores riscos de perfuração de raízes, e b) auto-rosqueantes, que requerem uma brocagem

* Professor Titular de Patologia na FOB-USP e na pós-graduação da FORP-USP.

** Professor Associado de Cirurgia na FOB-USP.

*** Professor de Implantodontia na Universidade do Sagrado Coração - USC

**** Mestre e Doutora pela FOB-USP e Ortodontista em Bauru.

***** Pós-Graduando em Patologia na FOB-USP. 

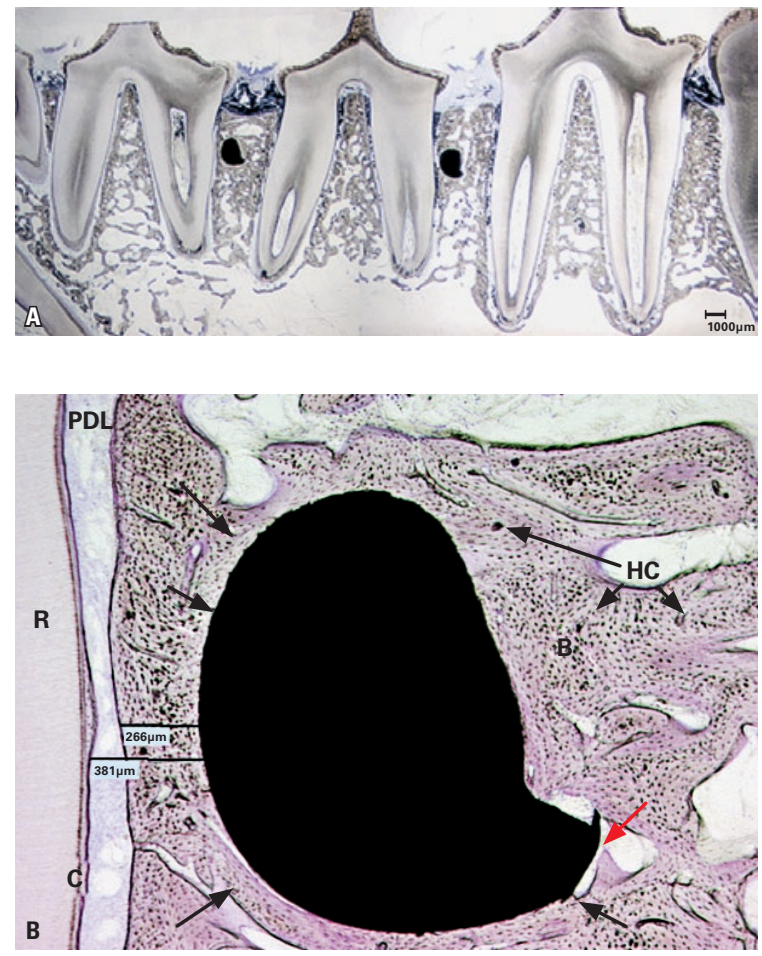

FIGURA 1 - Mandíbula de cão em que Vannet et al. ${ }^{39}$, em 2007, avaliaram histometricamente a osseointegração de mini-implantes após 6 meses de ancoragem esquelética: $\mathbf{A})$ a inserção foi entre as raízes dos segundo/terceiro e do terceiro/quarto pré-molares e os cortes teciduais obtidos de 70 micrômetros de espessura; B) a coloração com azul de toluidina na microscopia óptica revelou quase $100 \%$ de osseointegração, indicada pelas setas $(C=$ cemento; $R=$ raiz; $\mathrm{B}=$ osso; $\mathrm{PDL}=$ ligamento periodontal; $\mathrm{HC}=$ canais de Havers;). A seta vermeIha indica uma pequena área óssea sem osseointegração. A distância entre 0 mini-implante e o ligamento periodontal intacto foi de $2,66 \mathrm{~mm}$.

óssea prévia, por não possuírem pontas ativas.

7. Sua estrutura pode ser dividida em três partes: corpo, perfil transmucoso e cabeça. O perfil transmucoso representa a parte intermediária em contato com a mucosa. As suas partes podem variar quanto a formas e medidas, especialmente quanto à espessura e ao comprimento.

8. Os principais condicionantes de sucesso são: anatomia da gengiva, qualidade e/ou densidade do osso, distância ou proximidade das raízes e espessura da cortical óssea. Para Kyung et al. ${ }^{25}$, o sucesso no uso de mini-implantes depende dos seguintes fatores: habilidade do cirurgião, condição do paciente, seleção do local adequado, estabilidade inicial e higiene bucal.
9. Os mini-implantes são também denominados microimplantes, microparafusos e pinos de ancoragem, e fazem parte dos Dispositivos de Ancoragem Temporária ${ }^{3,4,28}$.

\section{QUESTIONAMENTOS SOBRE O USO CLÍNICO DOS MINIIIMPLANTES}

A evolução de uma idéia depende de permanente questionamento, o combustivel para a busca constante. Com os mini-implantes não haveria de ser diferente e algumas das perguntas mais freqüentes são:

\section{E se, durante sua colocação, o mini-implante tocar ou resvalar na raiz vizinha?}

Os dentes têm suas raízes recobertas por cementoblastos permeados pelas fibras de Sharpey, que correspondem às fibras periodontais que se inserem no cemento. Os cementoblastos protegem as raízes das reabsorções, que no osso são constantes. Esta proteção decorre da ausência de receptores na membrana dos cementoblastos para os mediadores que comandam a incessante remodelação óssea. Desta forma, as alterações hormonais, inflamações e estresses peri-radiculares não promovem reabsorções dentárias. Para as reabsorções dentárias iniciarem-se, algo deve remover os cementoblastos da superfície radicular, como, por exemplo, na movimentação ortodôntica por anoxia, nos traumatismos por ação mecânica direta e nas lesões periapicais crônicas por produtos bacterianos.

O toque ou o resvalamento do mini-implante na superfície radicular elimina os cementoblastos e as fibras de Sharpey e inicia-se uma reabsorção no local do traumatismo induzido. Toda reabsorção radicular pode ser iniciada pela remoção dos cementoblastos, mas, para manter-se por semanas, meses ou indefinidamente, requer mediadores no local, os mesmos do estresse celular e do processo inflamatório. Quando os mediadores desaparecem do local, pela remoção da causa inflamatória, os cementoblastos vizinhos proli- 
feram e recobrem novamente a superfície lesada, promovendo nova deposição de cemento e reinserção de fibras periodontais. Se houver tempo para ocorrer a reabsorcão radicular, ela será pequena, superficial e muito pouco duradora. Isto ocorre porque a área está livre de bactérias que, quando presentes, prolongam a inflamação indefinidamente. Em 2005, Asscherickx et al. ${ }^{6}$ elegantemente (Fig. 2) induziram, experimentalmente, o toque de mini-implantes em superfícies radiculares de dentes de cães. Detectaram, microscopicamente, que, após 12 semanas, um novo cemento já havia sido depositado, recobrindo a região, como mostra a figura 2 .

Estas evidências suportam a recomendacão: durante a colocação dos mini-implantes autoperfurantes, quando estes tocarem ou resvalarem na superfície radicular, o melhor a se fazer é remo- vê-los e redirecioná-los ou, ainda, replanejá-los. Não há necessidade de intervenções diretas, basta apenas acompanhá-los por 12 semanas, com obtenção de radiografia periapical a cada mês (Fig. 2). As reabsorções radiculares inflamatórias geram imagens radiográficas após três semanas. As reabsorções dentárias por substituição, decorrrentes de anquilose alveolodentária, demoram 3 meses para gerar imagens radiográficas.

O mini-implante em contato direto e constante com a raiz dentária não é recomendável, devendo-se removê-lo. O movimento dentário no alvéolo, decorrente da mastigação, a cada momento, induz lesão no local, eliminando alguns cementoblastos, e promove microáreas de inflamação, com formação constante de mediadores. Desta forma, pode-se promover severas reabsorções na interface mini-implante/raiz.
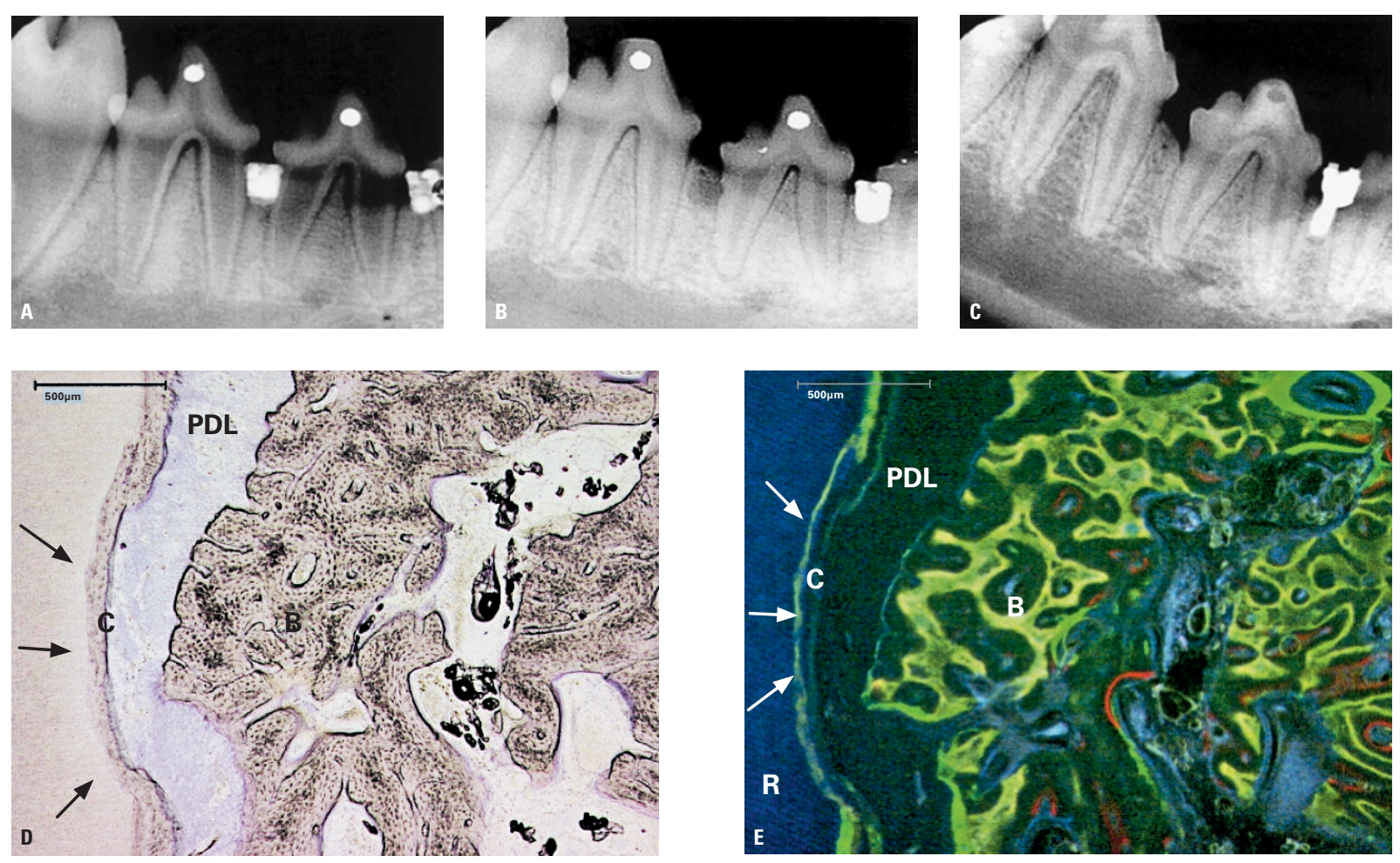

FIGURA 2 - Dentes de cães em que Asscherickx et al. ${ }^{6}$, em 2005, aplicaram mini-implantes que tocaram na superfície das raízes: A) radiografia imediatamente após a colocação; B) radiografia imediatamente após a remoção; C) radiografia 12 semanas depois da remoção, destacando-se a recomposição da superfície; D) microscopia da área tocada ou resvalada pelo mini-implante 12 semanas após sua remoção, em corte corado pelo azul de toluidina, no qual nota-se o reparo de cemento como indicam as setas; $\mathrm{E}$ ) microscopia da mesma área pela técnica da fluorescência. $(\mathrm{C}=$ cemento; $\mathrm{PDL}=$ ligamento periodontal; $\mathrm{B}=0 \mathrm{sso} ; \mathrm{R}=\mathrm{raiz})$. 


\section{O que fazer quando ocorre a perfuração de raiz?}

Os mini-implantes autoperfurantes possuem um terço médio inferior bastante afinalado e a ponta pró-ativa. São mais simples quanto ao protocolo cirúrgico, reduzem a possibilidade de lesão de raízes e proporcionam melhor estabilidade primária, em relação ao auto-rosqueantes. Se tocarem nas raízes, as chances de desviarem ou resvalarem são muito grandes, pois não precisam de brocagem prévia. No caso dos mini-implantes auto-rosqueantes, a brocagem prévia pode perfurar a raiz.

O importante, nos casos de perfuração acidental de raiz dentária durante a colocação de miniimplantes, é a ausência de contaminação. Nesta situação, a pergunta a se fazer será: a perfuração chegou ou não até a polpa e canal radicular?

Se perfurou o cemento e a dentina,sem afetar a polpa, a conduta deve ser a mesma de quando ocorre toque ou resvalamento do mini-implante. Deve-se removê-lo e redirecioná-lo ou, então, replanejar sua colocação. Quanto ao dente perfurado sem comprometimento da polpa, ocorrerá reabsorção radicular por algumas semanas, a inflamação de origem traumática e cirúrgica irá, gradativamente, desaparecendo, com seus mediadores mantenedores do processo reabsortivo, visto que não houve contaminação bacteriana. Entre 3 e 6 meses, a tendência será dos tecidos periodontais voltarem à normalidade, com recobrimento da área por novo cemento e reinserção das fibras periodontais. As radiografias periapicais devem ser mensais até a volta completa do espaço periodontal à regularidade normal.

Se a dentina for perfurada e a polpa e o canal radicular forem atingidos, deve-se lembrar da capacidade reparatória dos tecidos pulpares e periodontais. Em casos de fraturas horizontais radiculares, são numerosos os relatos em que o profissional imediatamente aproxima, ao máximo, ambos os fragmentos radiculares, imobiliza as coroas por esplintagem e, após alguns meses, tem-se a consolidação da linha de fratura. Externamente, haverá deposição de novo cemento e, internamente, de dentina reacional e/ou reparatória. A polpa continua com vitalidade e pode, eventualmente, sofrer envelhecimento precoce ou evoluir para a metamorfose cálcica. No caso da perfuração pelo mini-implante, o traumatismo e a lesão pulpar e periodontal são muito menores e localizados. A polpa pode reparar-se internamente, com deposição de dentina reacional ou reparatória, e envelhecer focalmente. Os tecidos periodontais formarão novo cemento e ligamento.

A possibilidade de necrose pulpar existe, mas para isto a lesão pulpar deve ter sido muito grande, com rompimento ou esmagamento dos vasos sanguíneos, e esta situação não deve ser a usual, pois na brocagem, antes da colocação do miniimplante auto-rosqueante, isto provavelmente foi percebido. Se houver a colocação do mini-implante auto-rosqueante, a possibilidade de necrose pulpar na raiz envolvida é quase absoluta.

Todas estas considerações sobre a perfuração da raiz e as reações pulpares são por analogia e extrapolação dos conhecimentos sobre a biologia pulpar, decorrentes do traumatismo dentário, fraturas radiculares, exposições pulpares acidentais e pulpotomias. Especificamente sobre este tema, os trabalhos experimentais e casuísticas de casos em humanos não estão ainda apresentados na literatura.

\section{Por que ocorrem mucosites e hiperplasias teciduais perimini-implantares?}

O ponto mais frágil de um mini-implante sem mobilidade e utilizado como ancoragem temporária, do ponto de vista biológico, corresponde à interação com os tecidos epiteliais da mucosa. O epitélio une-se ao perfil transmucoso do miniimplante por meio de hemidesmossomos e outras formas de união, incluindo-se substâncias cementantes secretadas na interface de ambas as estruturas. O epitélio nesta interface, provavelmente, prolifera para procurar imitar um epitélio juncio- 
nal, tal como ocorre com os implantes dentários convencionais.

Os biofilmes microbianos formam-se nas superfícies bucais, naturais ou não, quando houver deficiente higienização. Os biofilmes como películas representam verdadeiros condomínios microbianos, que aumentam gradativamente e interpõem-se na interface epitélio/mini-implante, induzindo um processo inflamatório semelhante à gengivite, podendo seguir-se da periodontite, se houver comprometimento dos tecidos ósseos subjacentes. No caso dos mini-implantes, teremos a mucosite e, se o processo seguir adiante, a perimini-implantite, com comprometimento de sua fixação e decorrente perda do dispositivo (Fig. 3).

Alguns mini-implantes apresentam, em seus designs, uma discreta aleta circular ou aba metálica acima do perfil transmucoso, na porção mais próxima de sua cabeça. Esta aba metálica, aparentemente, protege a linha da interface miniimplante/mucosa na superfície externa, mas, provavelmente, esta proteção seja mais física do que microbiana, pois deve favorecer a formação e manutenção de biofilme microbiano e pode dificultar o acesso de escovas e anti-sépticos neste local. Pesquisas poderiam ser feitas a esse respeito.

As mucosites e perimini-implantites ocorrem mesmo em mini-implantes bem instalados, mas em decorrência da formação de biofilmes microbianos sobre as partes expostas ao meio bucal e sem a higienização adequada.

\section{E as hiperplasias teciduais perimini-implantares?}

O reparo da pele e mucosas se faz com a formação de tecido de granulação que preenche os espaços perdidos e dá origem a um novo tecido conjuntivo, reconstituindo a região afetada por uma lesão qualquer.

O tecido epitelial de revestimento tem como função principal isolar o meio interno do meio externo. Quando ocorrem pequenos rompimentos epiteliais, tal como nas rachaduras labiais por ressecamento, pequenas lesões peri-ungueais, rebarbas em coroas provisórias e bandas ortodônticas, geralmente estão associados à presença de uma microbiota de baixa virulência. Nesta situação, o tecido conjuntivo, para se defender e prontamente
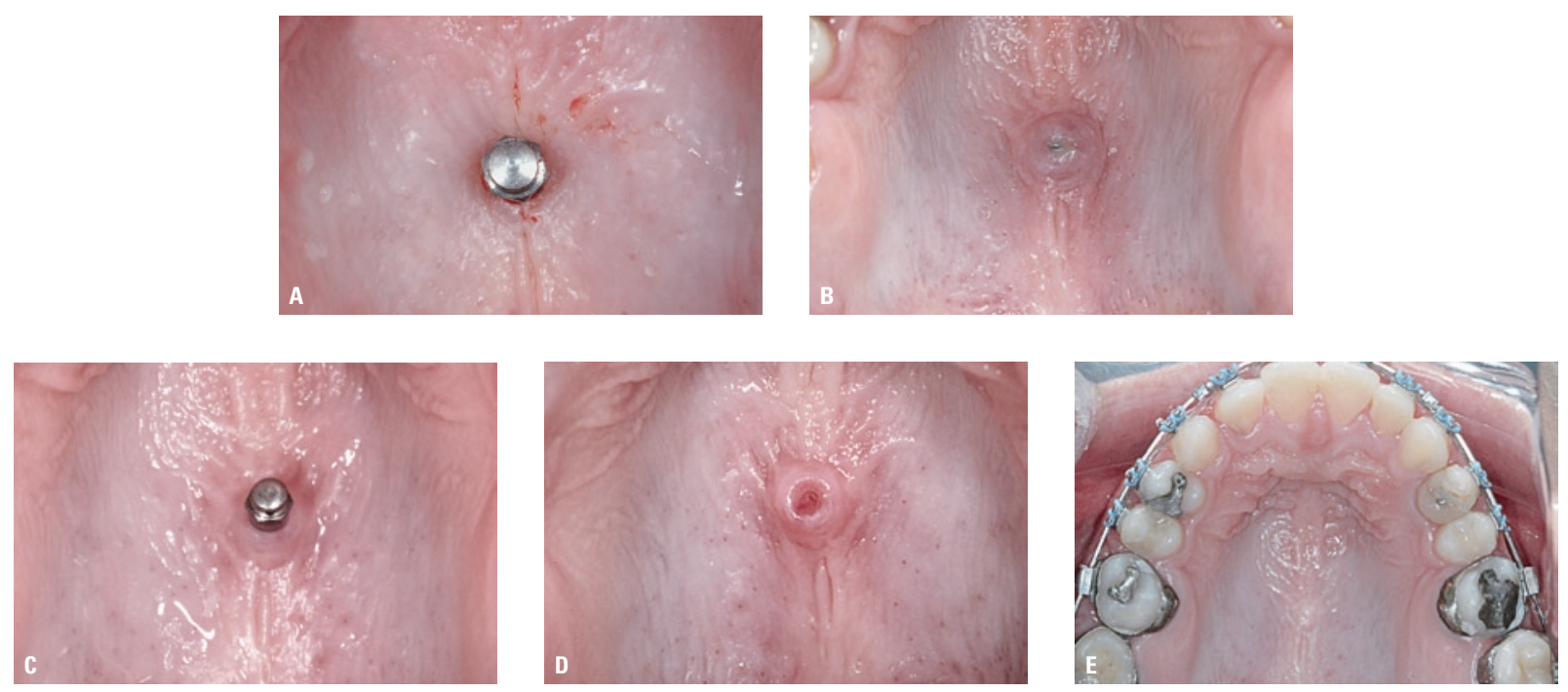

FIGURA 3 - Mini-implante logo após ser inserido no palato duro (A) em paciente de 25 anos, usuária de contraceptivo. Um mês depois (B) houve recobrimento da cabeça do mini-implante por tecido hiperplásico da mucosa bucal, tal qual um granuloma piogênico/hiperplasia fibrosa inflamatória, apesar da precisa higienização por parte da paciente. Um mês depois, o mini-implante revelava intensa mobilidade por perimini-implantite (C), sendo facilmente removido (D). Três meses depois (E) a mucosa palatina voltou ao normal, com discreta cicatriz na linha média. 
restabelecer a normalidade, promove a formação do tecido de granulação na região, juntamente com a proliferação do revestimento epitelial.

Mas, em crianças, adolescentes, adultos jovens, mulheres grávidas ou sob medicação contraceptiva (Fig. 3), esta capacidade reacional pode ser muito maior, exacerbada enfim. O tecido de granulação, em suas fases iniciais e intermediárias, se caracateriza pela angiogênese e estas pessoas nas situações mencionadas têm um aumento nos níveis sérico e teciduais de fatores estimuladores da angiogênese.

Nas microáreas expostas, em pessoas neste tipo de situação, o tecido de granulação exacerbadamente formado gera um aumento de volume e caracteriza o granuloma piogênico e o pólipo pulpar, por exemplo. Estas lesões representam uma hiperplasia angiomatosa do tecido de granulação. Este aumento de volume avermelhado e sangrante pode ocorrer ao redor dos mini-implantes (Fig. 3), especialmente na interface epitélio/mini-implante recoberta por biofilme microbiano.

A inflamação perimini-implantar pode deixar de ser caracterizada apenas por uma área avermelhada e periférica, para dar lugar a um aumento volumétrico festonado, regular ou irregular, sangrante e muito frágil em sua manipulação (Fig. 3). O epitélio vizinho é estimulado a hiperplasiar-se, para procurar recobrir este aumento volumétrico de tecido de granulação. Algumas destas hiperplasias perimini-implantares são mais avermelhadas, mas algumas têm áreas rosadas e firmes, locais onde o epitélio hiperplásico está exercendo sua função de revestimento (Fig. 3).

O tratamento das mucosites e hiperplasias perimini-implantares deve ser iniciado com a remoção da causa principal, os biofilmes microbianos, e detecção de prováveis rebarbas metálicas, restos alimentares interpostos e outros irritantes locais de baixa intensidade e longa duração. A regressão acontece em 24 a 48h. Em casos de persistência, deve-se procurar novamente as causas locais. Quando o crescimento tecidual for muito grande, sem possibilidade de regressão espontânea pode-se promover a remoção cirúrgica dos tecidos aumentados.

\section{Mini-implantes podem dar início a osteomielites?}

As osteomielites são lesões inflamatórias caracterizadas por extensas áreas de comprometimento ósseo com reabsorção desordenada, exsudato purulento e até múltiplas fístulas. Alguns sinais e sintomas podem ser sistêmicos, como febre, prostração e astenia. Inflamações ósseas limitadas a uma determinada área e com predomínio de neoformação óssea, esclerose e sem repercussões sistêmicas são identificadas como osteítes.

As osteomielites apenas ocorrem em pacientes com doenças de base que levam a uma debilidade orgânica ou em pacientes com doenças ósseas esclerosantes no local de ocorrência. Entre as doenças sistêmicas de base que podem estar associadas às osteomielites estão o diabete melito descompensado, imunossupressão, estados leucêmicos, anemias, etilismo, senilidade e outros. Entres as lesões ósseas esclerosantes que, quando contaminadas, podem dar origem às osteomielites estão a displasia cemento-óssea florida, doença de Paget e outras.

Em pacientes sistemicamente saudáveis e sem doenças ósseas esclerosantes praticamente não ocorrem osteomielites. Se isto acontecer os pacientes devem ser minuciosamente avaliados e, provavelmente, se determinará alguma destas doenças debilitantes sistêmicas. Isto ajuda a explicar porque, apesar das mais variadas situações clínicocirúrgicas em que há contaminação bucal, as osteomielites nos maxilares são pouco freqüentes.

Nos casos de mini-implantes, por extrapolação, a possibilidade de indução de osteomielites é extremamente pequena, pois, precedendo a sua instalação, deve-se sempre realizar uma minuciosa anamnese, exame clínico e avaliação do quadro sistêmico e ósseo local. Em casos de pacientes com doenças sistêmicas debilitantes, uma vez compensadas ou corrigidas pelo tratamento médico, o pa- 
ciente retorna à condição de normalidade.

Em suma, a instalação de mini-implantes representa um procedimento clínico-cirúrgico simples, mas que expõe e comunica o meio interno com o meio externo, em um ambiente altamente contaminado como o meio bucal. A avaliação da condição sistêmica e óssea do paciente é importante, tanto quanto a sua conscientização sobre a boa higienização, fundamental para o sucesso do procedimento. Por muitos dias, o meio interno estará separado do meio externo contaminado por uma tênue barreira epitelial, muito embora eficiente, representada pela interface mini-implante/ mucosa.

\section{CONSIDERAÇÕES FINAIS}

O uso dos mini-implantes alargou os horizontes da Ortodontia e ampliou a interface da Implantologia. Muitos aspectos dos mini-implantes ainda precisam ser esclarecidos, mas a declaração de Bezerra em um simpósio ${ }^{7}$ sobre ancoragem ortodôntica, após descrever um minucioso levantamento de literatura sobre o tema ${ }^{8}$, chamou-nos a atenção: "O fato das evidências científicas não estarem acessíveis não inviabiliza o recurso. Se funciona bem e tem área de aplicação clínica é muito importante que professores, entidades de

\section{REFERÊNCIAS}

1. AKIN-NERGIZ, N. et al. Reactions of peri-implant tissues to continuous loading of osseointegrated implants. Am. J. Orthod. Dentofacial Orthop., St. Louis, v. 114, no. 3, p. 292 298, 1998.

2. ALDIKAÇTI, M. et al. Long-term evaluation of sandblasted and acid-etched implants used as orthodontic anchors in dogs. Am. J. Orthod. Dentofacial Orthop., St. Louis, v. 125, no. 2, p. 139-147, 2004.

3. ARAÚJO, T. M. Recursos para ativação do sistema e controle de higiene periimplantar. Implant News, São Paulo, v. 3, n. 4, p. 406-407, jul./ago. 2006.

4. ARAÚJO, T. M. et al. Ancoragem esquelética em Ortodontia com miniimplantes. Rev. Dental Press Ortodon. Ortop. Facial, Maringá, v. 11, n. 4, p. 126-156, jul./ago. 2006. ensino, universidades e outros centros de pesquisa trabalhem com mais vigor, para encontrarmos as respostas." Singelamente, apresentamos algumas sugestões para futuros trabalhos sobre o uso de mini-implantes na prática ortodôntica:

1. Reações pulpares e periodontais após o toque e/ou resvalamento de mini-implantes, para fundamentar a prevenção, conduta e o tratamento.

2. Reações pulpares e periodontais após a perfuração radicular por mini-implantes.

3. Grau de influência do design de mini-implantes na formação e distribuição de biofilmes microbianos, quando expostos no meio bucal.

4. Morfologia dos tecidos da mucosa bucal na interface com mini-implantes, especialmente do epitélio, e mecanismos de interação nas diversas áreas da mucosa bucal.

5. Estudo comparativo das características microscópicas de mucosites e perimini-implantites com a gengivite e periodontite.

6. Estudo comparativo das características clínicas e microscópicas das hiperplasias periminiimplantares com o granuloma piogênico e hiperplasias fibrosas inflamatórias na mucosa bucal.

7. Relatos de casuísticas de acidentes e lesões associadas ao uso dos mini-implantes como contribuição para a sua prevenção e tratamento.
5. ARCURI, C. et al. Five years of experience using palatal miniimplants for orthodontic anchorage. J. Oral Maxillofac. Surg. Philadelphia, v. 65, no. 12, p. 2492-2497, 2007.

6. ASSCHERICKX, K. et al. Root repair after injury from miniscrew. Clin. Oral Implants Res., Copenhagen, v. 16, no. 5, p. 575-578, 2005.

7. BEZERRA, F. Ancoragem ortodôntica com microparafusos de titânio. Implant News, São Paulo, v. 3, n. 4, p. 397-399, jul./ ago. 2006.

8. BEZERRA, F. Evidências clínicas e científicas dos miniimplantes ortodônticos. Implant News, São Paulo, v. 3, n. 4, p. 400-401, jul./ago. 2006.

9. BÜCHTER, A. et al. Load-related implant reaction of miniimplants used for orthodontic anchorage. Clin. Oral 
Implants Res., Copenhagen, v. 16, no. 4, p. 473-479, 2005.

10. CARANO, A. et al. Clinical applications of the miniscrews anchorage system. J. Clin Orthod., Boulder, v. 39, no. 1, p. 9-42, Jan. 2005.

11. CHEN, F. et al. Anchorage effects of a palatal osseointegrated implant with different fixation: a finite element study. Angle Orthod., Appleton, v. 75, no. 4, p. 593-601, 2005

12. CHENG, S. J. et al. A prospective study of the risk factors associated with failure of mini-implants used for orthodontic anchorage. Int. J. Oral Maxillofac. Implants, Lombard, v. 19, no. 1, p. 100-106, Jan./Feb. 2004.

13. $\mathrm{CHOI}, \mathrm{B}$. H.; ZHU, S. J.; KIM, Y. H. A clinical evaluation of titanium miniplates as anchors for orthodontic treatment. Am. J. Orthod. Dentofacial Orthop., St. Louis, v. 128, no. 3, p. 382-384, 2005

14. CHUNG, K.; KIM, S-H.; KOOK, Y. C. Orthodontic microimplant for distalization of mandibular dentition in Class III correction. Angle Orthod., Appleton, v. 75, no. 1, p. 119-128, 2004.

15. COUSLEY, R. Critical aspects in the use of orthodontic palatal implants. Am. J. Orthod. Dentofacial Orthop., St. Louis, v. 127, no. 6, p. 723-729, 2005

16. EVANS, A. W.; LEESON, R. M. A.; PETRIE, A. Correlation between a patient-centred outcome score and surgical skill in oral surgery. Br. J. Oral Maxillofac Surg., Edinburgh, v. 43, no. 6, p. 505-510, 2005.

17. GELGÖR, I. E. et al. Intraosseous screw-supported upper molar distalization. Angle Orthod., Appleton, v. 74, no. 6, p. 838-850, 2004.

18. GRAY, J. B. et al. Studies on the efficacy of implants as orthodontic anchorage. Am. J. Orthod. Dentofacial Orthop., St. Louis, v. 83, no. 4, p. 311-317, 1983.

19. GÜNDÜZ, E. et al. Bone regeneration by bodily tooth movement: dental computed tomography examination of a patient. Am. J. Orthod. Dentofacial Orthop., St. Louis, v. 125, no. 1, p. 100-106, 2004

20. GÜNDÜZ, E. et al. Acceptance rate of palatal implants: a questionnaire study. Am. J. Orthod. Dentofacial Orthop., St. Louis, v. 126, no. 5, p. 623-626, 2004.

21. HERMAN, R. J.; CURRIER, F.; MIYAKE, A. Mini-implant anchorage for maxillary canine retraction: a pilot study. Am. J. Orthod. Dentofacial Orthop., St. Louis, v. 130, no. 2, p. 228-235, 2006.

22. HUANG, L. H.; SHOTWELL, J. L.; WANG, H. L. Dental implants for orthodontic anchorage. Am. J. Orthod. Dentofacial Orthop., St. Louis, v. 127, no. 6, p. 713-722, 2005

23. KELES, A.; ERVERDI, N.; SEZEN, S. Bodily distalization of molars with absolute anchorage. Angle Orthod., Appleton, v. 73 , no. 4, p. 471-482, 2003

24. KIM, J. W.; AHN, S. J.; CHANG, Y. I. Histomorphometric and mechanical analyses of the drill-free screw as orthodontic anchorage. Am. J. Orthod. Dentofacial Orthop., St. Louis, v. 128, no. 2, p. 190-194, 2005.

25. KYUNG, H. M. et al. Development of orthodontic microimplants for intraoral anchorage. J. Clin. Orthod., Boulder, v. 37, no. 6, p. 321-328, June 2003.

26. LABOISSIÈRE JÚNIOR, M. A. Aspectos estruturais dos microparafusos ortodônticos. Implant News, São Paulo, v. 3, n. 4, p. 404-405, jul./ago. 2006.

27. LIOU, E. J. W.; PAI, B. C. J.; LIN, J. C. Y. Do miniscrews remain stationary under orthodontic forces? Am. J. Orthod. Dentofacial Orthop., St. Louis, v. 126, no. 1, p. 42-47, 2004.
28. MAH, J.; BERGSTRAND, F. Temporary anchorage devices: a status report. J. Clin. Orthod., Boulder, v. 39, no. 3, p. 132-136, Mar. 2005

29. MIYAWAKI, S. et al. Factors associated with the stability of titanium screws placed in the posterior region for orthodontic anchorage. Am. J. Orthod. Dentofacial Orthop., St. Louis, v. 124, no. 4, p. 373-378, 2003.

30. OHASHI, E. et al. Implant vs screw loading protocols in Orthodontics: a systematic review. Angle Orthod., Appleton, v. 76, p. 721-727, 2006

31. OHMAE, M. et al. A clinical and histological evaluation of titanium mini-implants as anchors for orthodontic intrusion in the beagle dog. Am. J. Orthod. Dentofacial Orthop., St. Louis, v. 119, no. 5, p. 489-497, 2001.

32. OHNISHIA, H. et al. A mini-implant for orthodontic anchorage in a deep overbite case. Angle Orthod., Appleton, v. 75, no. 3, p. 444-452, 2005.

33. OYONARTE, R. et al. Peri-implant bone response to orthodontic loading: Part 1. A histomorphometric study of the effects of implant surface design. Am. J. Orthod. Dentofacial Orthop., St. Louis, v. 128, no. 2, p. 173-181, 2005.

34. OYONARTE, R. et al. Peri-implant bone response to orthodontic loading: Part 2. Implant surface geometry and its effect on regional bone remodeling. Am. J. Orthod. Dentofacial Orthop., St. Louis, v. 128, no. 2, p. 182-189, 2005.

35. ROBERTS, W. E. et al. Implant-anchored orthodontics for partially edentulous malocclusions in children and adults. Am. J. Orthod. Dentofacial Orthop., St. Louis, v. 126, no. 3, p. 302-304, 2004

36. SCHNELLE, M. A. et al. A radiographic evaluation of the availability of bone for placement of miniscrews. Angle Orthod., Appleton, v. 74, no. 6, p. 832-837, 2004.

37. SHERWOOD, K. H.; BURCH, J. G.; THOMPSON, W. J. Closing anterior open bites by intruding molars with titanium miniplate anchorage. Am. J. Orthod. Dentofacial Orthop., St. Louis, v. 122, no. 6, p. 593-600, 2002.

38. SUGAWARA, J. et al. Distal movement of mandibular molars in adult patients with the skeletal anchorage system. Am. J. Orthod. Dentofacial Orthop., St. Louis, v. 125, no. 2, p. 130-138, 2004

39. VANNET, B. V.; SABZEVAR, M. M.; WEHRBEIN, H.; ASSCHERICKX, K. Osseointegration of miniscrews: a histomorphometric evaluation. Eur. J. Orthod., Oxford, v. 29 no. 5, p. 437-442, 2007

40. VILLELA, H. M. Microparafuso ortodôntico de titânio autoperfurante: novas perspectivas para ancoragem esquelética. Implant News, São Paulo, v. 3, n. 4, p. 402-403, jul./ago. 2006.

41. VILLELA, H. M. Microparafusos ortodônticos de titânio autoperfurantes: mudando os paradigmas da ancoragem esquelética na Ortodontia. Implant News, São Paulo, v. 3 n. 4, p. 369-375, jul./ago. 2006

42. WEHRBEIN, H.; GOLLNER, P. Skeletal anchorage in Orthodontics-basics and clinical application. J. Orofac. Orthop., München, v. 68, no. 6, p. 443-461, 2007.

43. WIECHMANN, D.; MEYER, U.; BUCHTER, A. Success rate of mini- and micro-implants used for orthodontic anchorage: a prospective clinical study. Clin. Oral Implants Res., Copenhagen, v. 18, no. 2, p. 263-267, 2007.
Endereço para correspondência

Alberto Consolaro

E-mail: alberto@fob.usp.br 